\title{
Lepromin stimulates interleukin-2 production and interleukin-2 receptor expression in situ in lepromatous leprosy patients
}

\author{
B J LONGLEY, ABEBE HAREGEWOIN, WILLIAM DE BEAU- \\ MOUNT, K A SMITH \& T GODAL \\ Columbia Presbyterian Medical Center, New York, New York, \\ U.S.A., Armauer Hansen Research Institute (AHRI), Addis Ababa, \\ Ethiopia, University of Cincinnati Medical Center, Cinncinati, Ohio, \\ USA, All Africa Leprosy Rehabilitation and Training Center (ALERT) \\ Hospital, Addis Ababa, Ethiopia, Dartmouth Medical School, Hano- \\ ver, New Hampshire, U.S.A., Laboratory for Immunology, The Radi- \\ um Hospital, Oslo, Norway
}

\section{Introduction}

The granulomatous skin lesions of lepromatous leprosy are composed of poorly differentiated macrophages containing many Mycobacterium leprae (1). They show few lymphocytes compared to tuberculoid leprosy lesions and an increased «T-suppressor to T-helper» ratio $(2,3,4,5)$ due mainly to a lack of «T-helper» lymphocytes (2). Lepromatous lesions also show decreased numbers of Langerhans' (OKT6(+)) cells $(2,3,4,6)$.

Attempts to understand the immune defect in leprosy have focused on abnormalities of lepromatous patients' immune cascade. In vitro proliferation of T-lymphocytes in response to $M$. leprae is decreased in lepromatous patients when compared to tuberculoid patients (7). Studies by Haregewoin et al $(8,9)$ have shown that adding Interleukin-2 (IL-2) synergistically increases the proliferative resonse of lepromatous lymphocytes to $M$. leprae in vitro. IL-2 also increases the production of macrophage activation factors, such as gamma interferon, by lepromatous lymphocytes in vitro (10). However, other researchers have suggested a block in the immune cascade at the level of IL-2 receptor (IL-2R) expression (11). Immunohistochemical studies of naturally occurring leprosy lesions show that in situ IL-2 production is barely detectable in lepromatous patients unlike tuberculoid patients $(2,4)$. Modlin et al (4) have found equivalent numbers of IL-2R bearing cells in tuberculoid and lepromatous lesions, whereas we found decreased numbers of IL-2R cells in lepromatous lesions (2). Although there is disagreement as to the exact mechanism, these observations together suggest that lepromatous patients' inability to kill $M$. leprae involves a lack of IL-2 induced T-lymphocyte proliferation. Whether this necessarily means that lepromatous patients are incapable of producing IL-2 or IL-2R expressing cells is unclear from previously published work. Is it possible that the primary defect occurs elsewhere in the immune reponse, such as at the level of antigen presenting cells? 
This question cannot be answered without information on the temporal sequence of events in the immune cascade. Reported in situ studies of naturally occurring leprosy lesions do not provide this information because the lesions studied are evolving very slowly, of ten over a period of years, and may be thought of as being in a steady state.

The lepromin skin test, consisting of an intradermal injection of killed $M$. leprae provides an opportunity to observe host reponse to the organism within a 28 day period (12-18). In tuberculoid leprosy patients the skin test induces formation of localized tuberculoid type granulomas over the course of 28 days. These lesions are essentially indentical to those seen in naturally occurring lesions in the same patients $(16,17,19)$. Lepromatous patients, on the other hand, fail to form organized granulomas in response to the same antigen challenge. In an attempt to determine the earliest point at which differences occur between tuberculoid and lepromatous patients in the immune cascade, we used immunohistochemical techniques in sequential analysis of lepromin tests of both tuberculoid and lepromatous patients. We constructed a model of the development of granulomas by tuberculoid leprosy patients in response to this acute challenge with $M$. leprae, and compared it to the response of lepromatous leprosy patients to the same dose of antigen.

\section{Patients and Methods}

\section{STUDY DESIGN}

The lepromin test is a routine test used at the All Africa Leprosy Rehabilitation and Training Center (ALERT) Hospital. Our study design called for biopsy of lepromin test sites at different times in the 28 day reaction. In order to control for possible individual differences in immune response an ideal study design might have been to administer multiple lepromin tests to each patient and obtain biopsies of skin before the initial test and again after each time period studied. This design could not be adopted for ethical and practical reasons as it would have required 7 separate biopsies from each patient. In addition, repeated doses of lepromin to the same individual could have substantially modified the response we were seeking to measure. Therefore, we chose to adminster two lepromin tests simultaneously to each patient in the study, one for biopsy in the early stages of the reaction and one for evaluation at 28 days. Then pooling the results from lepromatous patients into one group and tuberculoid patients into another, it has been possible to construct a longitudinal model of the reaction for each group. To make statistical comparisons we divided each of the patient groups into early and late phases of the reaction. Since the lepromin test has been shown to be sensitizing $(13,14$, $15,17)$ and to induce tuberculoid granuloma formation in $M$. leprae naive individuals we did not attempt to study them or individuals exposed to $M$. leprae without clinical infection.

\section{PATIENT POPULATION}

Results from the biopsies of 34 patient volunteers from the ALERT leprosy control program clinic form the basis of this report. Eighteen of the patients comprised the tuberculoid group (4 classified as polar tuberculoid (TT) and 15 as borderline tuberculoid (BT) patients). The remaining 16 patients were lepromatous (13 classified as polar lepromatous (LL) and 3 as borderline lepromatous (BL) patients). The three BL patients were near the lepromatous pole of the clinical spectrum and had no palpable induration at the test sites at $48 \mathrm{~h}$ or $28 \mathrm{~d}$. Moreover, only one of the three patients was included in the analysis of early stages of the reaction when we found our unexpected results, and his IL-2 production was lower than the two polar lepromatous patients at that time. Patients in the clinic had been initially classified by ALERT physician leprologists on the basis of history, physical examination, and laboratory tests. All patients had previous skin slit smears and biopsies. At the time of recruitment to the 
study each patient was examined, their chart reviewed, and their biopsies reviewed by one of us (JL). If there was any disagreement with the patient's primary diagnosis, the patient was excluded from the study. The study group consisted of 15 men and 19 women ranging in age from 19 to 70 years. All patients had been or were currently receiving Dapsone, and some had received short courses of Rifampicin as well (length of treatment ranged from 14 mounths to 12 years). Tuberculoid patients tended to have had shorter treatment histories than lepromatous patients. No patient had evidence of acid fast bacilli on skin slit smears taken during the last three clinic visits prior to enrollment in the study. After informed consent, as approved by the AHRI/ALERT research committee, each patient received two routine lepromin tests, one on the volar surface of each arm. These consisted of the intradermal injection of $0.1 \mathrm{ml}$ of standard lepromin containing $4 \times 10^{7}$ heat killed, armadillo derived $M$. le prae/ml, (Lepromin-A) provided by Dr. R.J.W. Rees, National Institute for Medical Research, London, through the IMMLEP program of UNDP/World Bank/WHO. The location of all test sites was recorded with precise measurements in relationship to scars, tatoos, other dermal markings, and anatomical landmarks. In addition, all sites which were to be biopsied within three days were circled with india ink, and the patients were requested not to wash the site. Test sites to be biopsied at later times were further identified by the injection of a small amount of sterile india ink into the skin on either side of the test site, equidistant from the center of the test site, when landmarks were judged insufficient. A biopsy of one of the two test sites was then taken at either $24 \mathrm{~h}(1 \mathrm{~d}), 72 \mathrm{~h}(3 \mathrm{~d}), 7 \mathrm{~d}, 14 \mathrm{~d}$, or $21 \mathrm{~d}$. The second test was read clinically at $28 \mathrm{~d}$ and in some cases biopsied.

\section{BIOPSY ANALYSIS}

Biopsies were taken with a standard, dermatologic biopsy punch. Each biopsy was divided into two halves. One half was used for routine histological diagnosis including determination of the percentage of the dermis infiltrated by granuloma, and the other was placed in an airtight plastic capsule, covered with O.C.T. Compound (Miles Laboratories, Inc., USA), snap frozen in liquid nitrogen, and stored at $-70^{\circ} \mathrm{C}$ until used. Six micron thick serial sections were cut onto micoscope slides on an Ames Cryostat II, fixed for $5 \mathrm{~S}$ in acetone at $4^{\circ} \mathrm{C}$, and air dried overnight at $\div 20^{\circ} \mathrm{C}$.

Immunohistochemical staining was done using a modification of the avidin-biotin horseradish peroxidase complex method (Vector Laboratories, Burlingame, California) $(20,2)$. Briefly, sections were fixed in acetone at $4^{\circ} \mathrm{C}$ for 10 minutes $\left(27^{\circ} \mathrm{C}\right.$ for cytoplastmic staining of IL-2), air dried for two minutes, washed in phosphate buffered saline, and incubated sequentially with the following reagents: normal horse serum, mouse hybridoma monoclonal antibody (also at $27^{\circ} \mathrm{C}$ for staining of IL-2), biotinylated horse anti-mouse-IgG serum, $0.3 \%$ $\mathrm{H}_{2} \mathrm{O}_{2}$ in PBS, followed by a $0.9 \%$ saline wash, and $1 \% \mathrm{CuSO}_{4}$ in $0.9 \%$ saline. Sections were counterstained with methylene blue, toluidine blue, or light green solutions, dehydrated and mounted in permount (Fischer Scientific, USA).

Alkaline phosphatase staining was done on tissue prepared and processed identically, except that after the incubation with biotinylated horse anti-mouse $\mathrm{IgG}$, the following reagents were used sequentially, alternating with PBS washes unless otherwise stated: $0.3 \% \mathrm{H}_{2} \mathrm{O}_{2}$ in Methanol, Avidin-alkaline phosphatase conjugate (Sigma, St. Louis, Mo.) in 0.1 N bicarbonate $\mathrm{pH} 9.4(21,22)$, DAB substrate (which we found reduced background staining), $0.5 \%$ tris buffered $0.9 \% \mathrm{NaCL}$ (no more PBS washes), alkaline phosphatase substrate $(0.5 \mathrm{mg} / \mathrm{ml}$ Napthal AS-MX phosphate, $1 \mathrm{mg} / \mathrm{ml}$ fast blue BB salt, $2 \mathrm{mM}$ levamisole HCL in $0.2 \mathrm{M}$ tris pH 8.2) (23), tap water wash. Some slides were counterstained with nuclear fast red. Slides were mounted in gelvatol. 
Cell counts were made of representative portions of specimen granulomas using an American Optical microscope with a $1 \mathrm{~cm}^{2}$ eye piece grid. Five-hundred to 1,000 stained cells were counted in each specimen when that many were present and cell counts adjusted to $1 \mathrm{~mm}^{2}$ of granuloma. When the number of stained cells was small, all stained cells in the section were counted. There was faint staining of histiocytic cells in the sections stained for the «helper/inducer» lymphocyte subset (see below) so we only counted small (8-10 microns in diameter) cells with a distinct dark rim of reaction product for these antibodies.

\section{MONOCLONAL ANTIBODIES}

Antibody titers employed for the study were determined by multiple dilutions and staining of several specimens. Titers are reported in parentheses following the antibody type. Primary mouse hybridoma monoclonal antibodies reacting with human antigens were generously provided as follows: anti-Tac (1:1500), reacting with the IL-2 receptor complex, from Dr. T. A. Waldman, National Cancer Institute, Bethesda, Maryland (24); DMS 1 (5 mcg/ml) reacting with unbound IL-2 (staining IL-2 producing cells), Dr. K. A. Smith (25); OKT8 (1:40), reacting with the suppressor/cytotoxic T lymphocyte subset, OKT4 (1:25), reacting with the helper/inducer T lymphocyte subset, OKT6 (1:50), reacting with Langerhans' cells $(26,27)$, from Dr. G. Goldstein, Ortho Pharmaceuticals, Raritan, N.J. Anti Leu3ab (neat), reacting with the helper/inducer T-lymphocyte subset and weakly with macrophages, and anti Leu2 (1:30), reacting with the cytotoxic/suppressor T-lymphocyte subset were purchased from Becton Dickenson, Moutain View, California. We elected to use counts of sections stained with the OKT8 and Leu3ab monoclonal antibodies for our calculations of the numbers of lymphocytes because they were easier to count than their counterparts. We defined the total number of lymphocytes in a given area as the sum of the OKT8 (+) plus the small, dark staining Leu3ab $(+)$ cells in that area.

\section{Results}

\section{TIME COURSE OF THE LEPROMIN REACTION}

Figure 1 shows the time course of the lepromin reactions in tuberculoid and lepromatous patients as defined by the total number of lymphocytes per $\mathrm{mm}^{2}$ of tissue in 6 micron thick sections from the center of the lepromin test site. It clearly reveals a biphasic response in tuberculoid patients, which corresponds to the early (Fernandez) and late (Mitsuda) phases seen clinically (12-18). We see that in lepromatous patients the early phase is blunted, and the late phase is almost totally aborted. The factor dominating the shapes of the curves in Figure 1 is the percentage of the dermis infiltrated by granuloma. Although the density of the lymphocytic infiltrate (i.e., lymphocytes $/ \mathrm{mm}^{2}$ of granuloma, data not shown) is some what greater in tuberculoid patients than in lepromatous patients, the shapes of the curves in Figure 1 are not greatly influenced by this factor.

\section{CELLULAR PHENOTYPE IN THE LEPROMIN REACTION}

Our past studies of naturally occurring leprosy (2) showed an increase in the absolute numbers of Leu 3/OKT4 (+) («T helper») cells in lesions along the clinical spectrum from polar lepromatous patients to polar tuberculoid patients. This gradient is responsible for the change in T-cell subset ratios («T helper to $\mathrm{T}$ suppressor ratios») reported by other groups $(3,4,5)$, because the absolute numbers of Leu 2/OKT8 (+) («T suppressor») cells are nearly constant across the spectrum. We expected to find a similar pattern of $\mathrm{T}$-cell subset ratios in lepromin test sites, so we were surprised to find a ratio of about 2.5 « T , cells for every one « $\mathrm{T}$ suppressor» cell in both lepromatous and tuberculoid patients throughout the course of the 


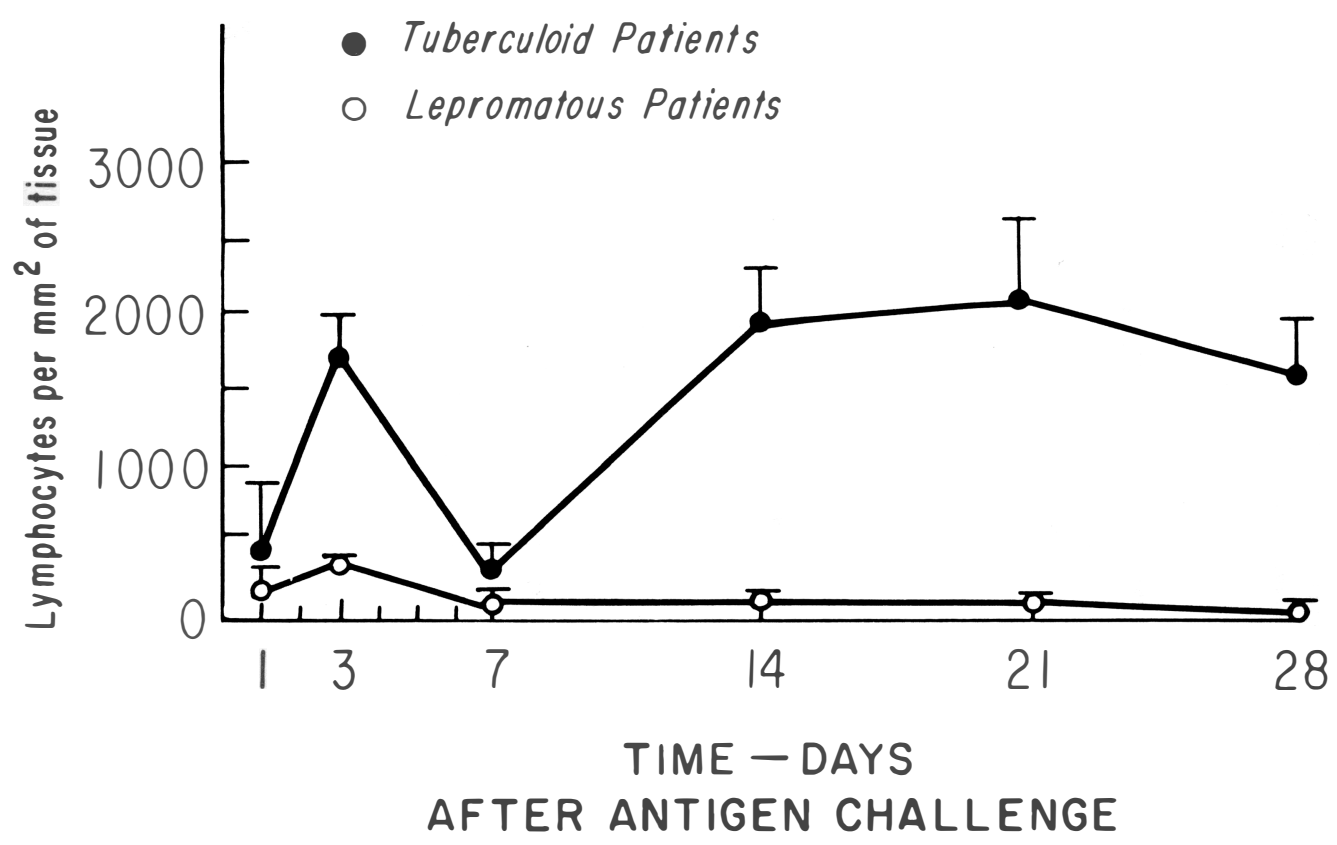

Figure 1: Mean numbers of lymphocytes per $\mathrm{mm}^{2}$ of tissue at various times during the lepromin skin test in tuberculoid and lepromatous patients. The values were determined by adding the numbers of OKT8 (+) cells and small, dark staining Leu3ab (+) cells per $\mathrm{mm}^{2}$ of samples of granuloma in 6 micron thick frozen sections of lepromin test sites and multiplying this sum by the percentage of the entire dermis infiltrated by granuloma as observed in the corresponding paraffin embedded sections. This method reduces the chances of sampling error due to the focal nature of the granulomatous infiltrate. At days 1, 3, 7 and 21, each point on the graph represents the mean value for 3 different patients. At day 14, four tuberculoid and 2 lepromatous patients were observed, and at day 28, two tuberculoid and two lepromatous patients were observed. Both of the tuberculoid patients and one of the two lepromatous patients at 28 days represent the second biopsy for these patients. Thus, 31 patients in all contributed 34 biopsies for this study. Twenty-nine contributed 1 biopsy each and 3 contributed 1 biopsy on each of 2 days. Range bars indicate one standard error.

reaction. Although there was some variation in the actual ratios at individual time points, the universal finding of greater numbers of $\mathrm{T}$ «helper» phenotype cells supports our claim that a simple preponderance of «T suppressor» cells is not responsible for the defect in lepromatous patients.

Figure 2 shows the mean number of cells per $\mathrm{mm}^{2}$ of tissue (DMS $1(+)$, OKT6 $\left.(+)\right)$ or the percentage of cells $(\mathrm{Tac}(+))$ present at various times during the course of the lepromin reaction. This presentation shows, for the first time, the kinetics of the development of a tuberculoid granuloma (Figure 2A, 2C, 2E). Histologically, during the early phase there were capillary endothelial swelling; dermal edema; central fibrinoid deposits («fibrinoid necrosis»); and infiltration by lymphocytes, histiocytes, polymorphonuclear leukocytes and occasional eosinophils and mast cells. IL-2 production was high at 24 hours, the first time point examined (Figure 2A), but IL-2 receptor expression was not noted until 72 hours, the second time point examined (Figure $2 \mathrm{C}$ ). The number of OKT6 $(+)$ cells per $\mathrm{mm}^{2}$ of tissue increased 
TUBERCULOID PATIENTS

LEPROMATOUS PATIENTS

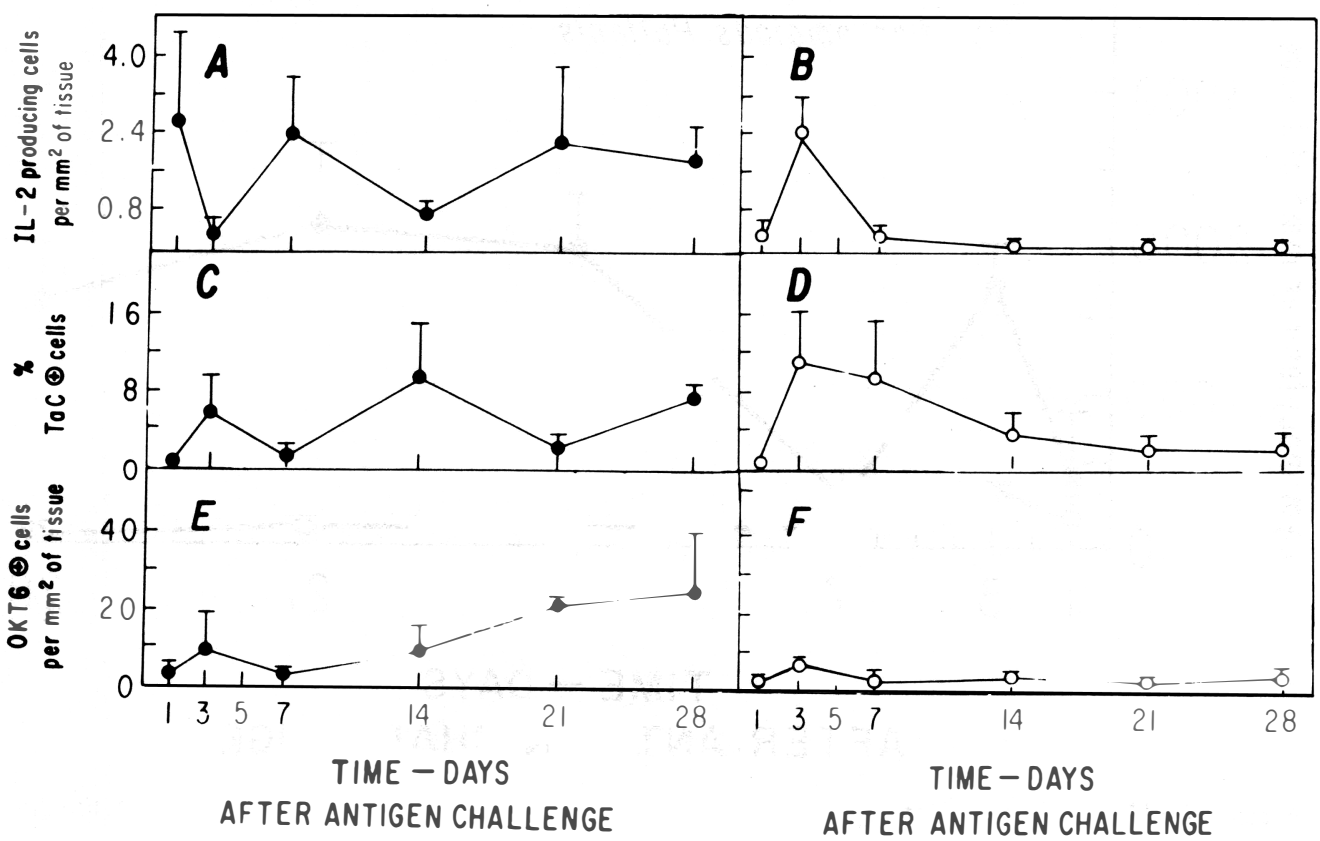

Figure 2: Observations of IL-2 producing cells (DMS-I (+) cells), IL-2 receptor bearing cells $(T a c(+)$ cells $)$, and Langerhans' cells $(O K T 6(+)$ cells) in lepromin test granulomas at various times in groups of tuberculoid and lepromatous patients. Points represent the mean values of several biopsies as described in Figure 1. Tuberculoid patients' values are in panels $A, C$, and E. Lepromatous patients' values are in panels $B, D$, and $F$. Panels $A$ and $B$ give the total number of IL-2 producing cells divided by the total area of dermal tissue seen on the individual biopsy slides. Panels $2 C$ and $2 D$ show the percentage of lymphocytes bearing the IL-2 receptor as defined by reactivity with anti-Tac monoclonal antibody. To evaluate cell percentages, cell counts were made in granulomas on 3 serial sections, each stained with anti-Tac, OKT8, or Leu2ab. The total number of each type of cell was calculated per $\mathrm{mm}^{2}$ of granuloma and the percentage IL-2 receptor bearing cells calculated as

$\frac{\text { NumberTac (+) }}{\text { Number OKT8 (+) + Leu3ab (+) }}$ cells $/ \mathrm{mm}^{2} \times 100$

Panels $2 E$ and $2 F$ show the number of OKT6 (+) cells per $\mathrm{mm}^{2}$ of dermal tissue.

from 24 to 72 hours, when the whole infiltrate was increasing (compare Figure 1 with Figure $2 \mathrm{E}$ ). The density of the OKT6 (+) infiltrate (the number of cells per $\mathrm{mm}^{2}$ of granuloma) was relatively constant throughout the reaction (data not shown).

At 7 days the total infiltrate as well as the numbers of Tac $(+)$ and OKT6 $(+)$ cells were at their lowest levels, although the number of IL-2 producing cells was high. Over the next 21 days, the infiltrate reappeared, with central areas of fibrinoid material surrounded by macrophages and lymphocytes. Granulocytes were rare. The central fibrinoid areas were gradually 
replaced by epithelioid macrophages as the lymphocyte mantle zones became more compact. During this time there was continued production of IL-2 and the presence of IL-2R bearing cells (Figures $2 \mathrm{~A}$ and $2 \mathrm{C}$ ). As in the early phase of the reaction, the number of OKT6 (+) cells closely paralleled the overall size of the infiltrate (compare Figure 2E and Figure 1). OKT6 (+) cells were best demonstrated in the mantle zone of the developing granulomas and appeared to lose the T6 antigen and/or their dendritic processes in the areas of epithelioid cell differentiation near the central fibrinoid deposits.

Figures $2 \mathrm{~B}, 2 \mathrm{D}$, and $2 \mathrm{~F}$ allow comparison of the lepromatous lepromin test with the tuberculoid model. As seen in Figure 1, the early lepromatous infiltrate was smaller than the early tuberculoid infiltrate, although it was composed of the same cell types. Despite the smaller size of the infiltrate, we see numbers of IL-2 producing cells and percentages of IL-2 receptor bearing cells which are similar to those seen in tuberculoid patients at the peak of the early phase of the response. IL-2 production quickly decays, and the percentage of IL-2R (+) cells follows a similar, although somewhat delayed, pattern. As seen in tuberculoid patients, the number of OKT6 $(+)$ cells most closely parallels the size of the infiltrate (compare Figure $2 \mathrm{~F}$ and Figure 1).

In order to obtain adequate statistical power to test for significant differences we pooled the biopsy results into two phases: early ( 24 and 72 hours) and late ( 7 to 28 days). In the early phase of the reaction there were no significant differences between the tuberculoid and lepromatous groups in mean absolute numbers of DMS1 $(+)$, OKT6 $(+)$, or Tac $(+)$ cells (or percentage of Tac $(+)$ cells) per $\mathrm{mm}^{2}$ of tissue at the reaction site. Thus, despite the lack of a clinical response in the lepromatous patients, there are many immunologic similarities between their early lepromin reaction and the tuberculoid reaction. On the other hand, in the late lepromatous reaction the numbers of DMS1 (+), OKT6 (+), and Tac (+) cells were significantly less (less than 0.05 by two tailed t-tests) than for each of the other three groups of observations (early tuberculoid, late tuberculoid, and early lepromatous).

IL-2 receptor expression (Tac epitope expression) by cells offers evidence of a functional antigen presenting mechanism $(28,29,30,31)$. It is not clear whether the absolute number of cells expressing IL-2 receptors, or the percentage of available cells expressing the IL-2 receptor is a better measure of this host antigen presenting mechanism. Although there were substantial absolute numbers of Tac $(+)$ cells at lepromatous test sites at 72 hours, and intense staining indicated many receptors per cell, the ability of lepromatous patients to generate Tac (+) cells is more obvious if one looks at the precentage of cells expressing the Tac antigen. Because there are fewer cells at lepromatous test sites than at tuberculoid test sites (Figure 1), the same absolute number of Tac $(+)$ cells represents a higher percentage of the cells infiltrating lepromatous test sites than tuberculoid sites. Graphing the percentage of Tac $(+)$ cells over time, rather than dichotomizing the data into early and late phases, shows an interesting pattern in lepromatous patients (Figure 2D). This rise and fall is similar to what is seen in vitro after stimulation of lymphocyte antigen receptor complexes and exposure to IL-2 $(28,29,30,31)$.

This presentation demonstrates that Tac epitope expression is negligible at 24 hours in vi$v o$ after antigen stimulation in both lepromatous and tuberculoid patients. In addition, IL-2 production (DMS1 $(+)$ cells), IL-2 receptor expression (Tac $(+)$ cells), and Langerhans' $($ OKT6 $(+))$ cell infiltrates are similar in the early phases of tuberculoid and lepromatous lepromin test. All three of these cell types are decreased in the late lepromatous reaction but not in the tuberculoid reactions. The number of OKT6 (+) Langerhans cells appears to be closely linked to the overall size of the infiltrate. 


\section{Discussion}

High levels of Tac epitope expression occur before IL-2 induced lymphocyte proliferation and are seen in vitro only after antigen receptor stimulation with subsequent expression of the high affinity IL-2 receptor and interaction of this receptor with IL-2 (31). We have not documented lymphocyte proliferation in situ, but our findings of Tac antigen and DMS1 (+) cells both indicate that the immune system is functional from the antigen presenting mechanism through IL-2 production and Tac epitope expression in lepromatous patients. Although the lepromatous dejfect may involve regulation of these processes, it is unlikely that the mechanisms themselves are fundamentally deranged.

At first glance, our findings seem at variance with results reported from our laboratories $(2,8)$ and others $(11)$ which have implicated lack of IL-2 or IL-2R as being crucial to the defect in lepromatous leprosy. The study reported here may offer a way of reconciling these disparate views because the individual components which we have measured are all transiently present in lepromatous patients in the early phase of the reaction. Slightly different patient populations or in vitro techniques may favor slightly different stages of this process, giving different responses to IL-2. We found a large variation in IL-2 and IL-2R in our patients, as indicated by the relatively large standard errors in Figure 2. Similar variability has been observed in larger samples $(2,4)$ and appears to be intrinsic to the process of granuloma formation. The amount of variability seen in these processes and the apparent fragility with which they are influenced in vitro suggest that abnormal IL-2 production and IL-2R expression are not primary events in the immunopathogenesis of lepromatous leprosy but are secondary to events occurring at an earlier stage of the response.

The finding of Langerhans' cells, IL-2 producing cells, and IL-2R bearing cells shows that lepromatous patients are capable of mustering these basic cell types in response to Lepromin A. The presence of the latter two cell types offers some evidence for a functional antigen presenting mechanism. Yet for some reason these cells fail to persist at lepromatous patient test sites, and the patients fail to form tuberculoid granulomas. These results could be seen with pathologic suppression, natural decay (down-regulation or attrition) due to lack of effective stimulation, or a combination of these factors. The results of our study are consistent with any of these possibilities. Although active suppression seems likely at least somewhere in the response, it is not clear that it is pathological, and documenting it will require techniques for following cellular control at the molecular level, prior to mRNA transcription (31). It is clear that to understand the relevance of these mechanisms we must be able to establish a time frame and identify the earliest stage at which they differ in lepromatous and tuberculoid patients.

There is currently no absolutely pure source of $M$. leprae. Lepromin A is extensively purified from the livers of armadillos infected with $M$. leprae. During its preparation, dilutions of lepromin are based on the concentration of bacilli, so it is not possible to make an exactly comparable substance to use as a control without $M$. leprae present. So although the armadillo is not native to Africa and our patients are therefore unlikely to be sensitized to armadillos, caution is advised in generalizing our results from the lepromin test to naturally occurring infections. However, we have described the local events leading to the formation of a tuberculoid granuloma in tuberculoid leprosy patients. The same stimulus in lepromatous patients fails to elicit tuberculoid granuloma formation, and therefore we have investigated a real difference in the immune response of these two groups.

Studies of the lepromin test reaction may be helpful in at least two ways. Because they can separate lepromatous type responses from tuberculoid type responses as early as 14 days after the application of the test, they may help evaluate the effects of immunotherapy on the total host defense. Lepromin test studies may also help to focus efforts for future research. In 
this latter respect our findings relating to the OKT6 (+) Langerhans' cell are of interest. The function of the Langerhans' cell in leprosy is not known. It may be an antigen presenting cell, a precursor of effector macrophages, and/or have some entirely different function. Whatever its function, we have shown that significantly more Langerhans' cells appear in the late tuberculoid response than in the lepromatous response. We conclude that the mechanism of lepromatous failure involves the regulation or function of these cells. The cause of this phenomenon may be an event occurring earlier in the immune response or it may be intrinsic to the Langerhans' cell itself.

\section{Acknowledgments}

We would like to acknowledge, first of all, the late Dr. Ayele Belehu. As Director of AHRI during the formulation and early stages of this project, his aid was invaluable. We would also like to thank Drs. Len Poulter, John Fenoglio, and Gabriel Godman for their help and encouragement. The research was funded by a grant from the Heiser Program for Research in leprosy.

\section{References}

1 Ridley DS and Jopling WH. Classification of leprosy according to immunity: A five groups system. Int J Lepr 1966; 34(3): 255-73.

2 Longley J, 'Haregewoin A, Yamaneberhan T, Warndorff Van Diepen T, Nisibami J, Knowles DM, Smith KA, and Godal T. In vivo responses to Mycobacterium leprae: Antigen presentation, Interleukin 2 production, and immune cell phenotypes in naturally occurring lesions. Int J Lepr 1985; 53: 385-94.

3 Van Voorhis CG, Kaplan G, Sarno et al. The cutaneous infiltrates in leprosy. Cellular characterization and the predominant T-cell phenotypes. NEJM 1982; 307: 1593-4.

4 Modlin RL, Hoffmann FM, Horowitz DA, Husmann LA, Gillis S, Taylor CR and Rea TH. In situ identification of cells in human leprosy granulomas with monoclonal antibodies to Interleukin-2 and its receptor. J Immunol 1984; 132(6): 3085-90.

5 Narayanan RB, Bhutani LK, Sharma AK and Nath I. T cell subsets in leprosy lesions: In situ characterization using monoclonal antibodies. Clin Exp Immunol 1983; 51: 421-9.

6 Breathrath AS, Birbeck MS, and Everall JD. Observations on Langerhans' cells in leprosy. Br J Dermatol 1962; 74: 243.

7 Godal T, Myslestad B, Samuels DR, Myrvang B. Characterization of the cellular immune defect in lepromatous leprosy: a specific lack of circulating Mycobacterium leprae-reactive lymphocytes. Clin Exp Immunol 1971; 9: 821.

8 Haregewoin A, Godal T, Mustafa AS, Belehu A, and Yemaneberhan T. T cell conditioned media reverses $\mathrm{T}$ cell unresponsiveness in lepromatous leprosy. Nature 1983; 303: $342-4$.

9 Haregewoin A, Mustafa AS, Helle I, Waters MRF, Leiker DL, and Godal T. Reversal by Interleukin-2 of the T-cell unresponsiveness of lepromatous leprosy to Mycobacterium leprae. Immunol Rev 1984; 80: 79.

10 Nogueira N, Kaplan G, Levy E, Sarno EN, Rishneu R, Granelli-Piperno A, Viera L, Gould VC, Levis W, Steinman R, Yip YK, and Cohn ZA. Defective interferon production in leprosy: reversal with antigen and Interleukin-2. J Exp Med 1983; 158: 2165-70.

11 Mohagheghpour N, Gelber RH, Larrick JW, Sasaki DS, Brennan PJ, and Engleman EG. Defective cell-mediated immunity in leprosy: Failure of $\mathrm{T}$ cells to respond to Mycobacterium leprae is associated with defective expression of Interleukin-2 receptors and is not reconstituted by Interleukin-2. J Immunol 1985; 135: 1443. 
12 Dharmendra, The active principle of Lepromin is a protein antigen of the bacillus. Lepr in India 1941; 13: 89, Reprinted in Lepr in India 1978; 50(1): 64.

13 Rees RJW. The significance of the lepromin reaction in man. Prog Allergy 1964; 8: 224.

14 WHO Expert Committee on Leprosy, 1970 Fourth Report. WHO Technical Report Series No. 459, Geneva.

15 Meyers WM, Kvernes S and Binford $\mathrm{CH}$. Comparisons of reactions to human and ar- madillo lepromins in leprosy. Int J Lep 1975; 43(4): 218.

16 Thomas J, Joseph M, Ramanujam K, Chacko CJG and Job CK. The histology of the Mitsuda reaction and its significance. Lepr Rev 1980; 52: 329.

17 Skinneses OK. In Chochrane RG (ed), Leprosy in Theory and Practice 1964; J. Wright Pub, Bistol.

18 Desikan KV, Mukherjee A, Ramu G, and Timu VD. Sequential histological study of the lepromin reaction. Int J Lepr 1983; 51(4): 473.

19 Dugan E, Modlin RL and Rea TH. An in situ immunohistochemical study of the Mitsuda reaction. Int J Lep 1985; 53: 404.

20 Hsu SM, Raine L and Fasnger H. Use of avidin-biotin-peroxidase complex (ABC) in immunoperoxidase techniques. J Histochem Cytochem 1981; 24(4): 577-80.

21 Bussolate $G$ and Gugliotta $P$. Non-specific staining of mast cells by avidin-biotin-peroxidase complex (ABC). J Histochem Cytochem 1983; 34(12): 1419-21.

22 Mason DY and Sammons R. Alkaline phosphatase and peroxidase for double immunoenzymatic labelling of cellular constituents. J Clin Path 1978; 31: 454-60.

23 Ponder BA and Wilson WM. Inhibition of endogenous tissue alkaline phosphatase with the use of alkaline phosphatase conjugates in immunohistochemistry. J Biochem Cytochem 1981; 29(8): 981-4.

24 Deppe JM, Lenord WJ, Robb RJ, Waldman TA and Green WC. Blockade of the Interleukin-2 receptor by anti-Tac antibody: Inhibition of human lymphocyte activation. J Immunol 1983; 131(2): 690-6.

25 Smith KA, Favata MF and Oroszlan S. Production and characterization of monoclonal antibodies to human Interleukin-2: Strategy and tactics. J Immunol 1983; 121: 1808-15.

26 Reinherz EL and Schlossman SF. Regulation of the immune response-inducer and suppressor T-lymphocyte subsets in human beings. NEJM 1980; 303(7): 370-6.

27 Fithian ES, Kung P, Goldstein G, Rubenfeld M, Fenoglio C, and Edelson RL. Reactivity of Langerhans' cells with hybridoma antibody. Proc Natl Acad Scr (USA) 1981; 78: 2541-4.

28 Cantrell DA and Smith KA. Transient expression of Interleukin-2 receptors: Consequences for T cell growth. J Exp Med 1983; 158: 1895-1911.

29 Robb RJ, Munck A and Smith KA. T cell growth factor receptors: Quantitation, specificity, and biological relevance. J Exp Med 1981; 145: 1455-74.

30 Larsson EL, Iscove NN and Coutinho A. Two distinct factors are required for induction of T cell growth. Nature 1980; 283; 664-7.

31 Smith KA and Cantrell DA. Interleukin 2 regulates its own receptors. Proc Natl Acad Sci (USA) 1985; 82: 864-868. 